\title{
Pediatrician preferences, local resources, and economic factors influence referral to a subspecialty access clinic
}

\author{
Matthew D. Di Guglielmo ${ }^{1,4}$, Jay S. Greenspan ${ }^{2,5}$ and Diane J. Abatemarco ${ }^{3,5}$ \\ ${ }^{1}$ Clinical Assistant Professor of Pediatrics, Sidney Kimmel Medical College of Thomas Jefferson University, \\ Philadelphia, PA, USA \\ ${ }^{2}$ Professor of Pediatrics, Sidney Kimmel Medical College of Thomas Jefferson University, Philadelphia, PA, USA \\ ${ }^{3}$ Associate Professor of Pediatrics, Sidney Kimmel Medical College of Thomas Jefferson University, \\ Philadelphia, PA, USA \\ ${ }^{4}$ Division of Gastroenterology, Hepatology, and Nutrition, Nemours/Alfred I. duPont Hospital for Children, \\ Wilmington, DE, USA \\ ${ }^{5}$ Department of Pediatrics, Nemours/Alfred I., duPont Hospital for Children, Wilmington, DE, USA
}

\begin{abstract}
Background: Pediatric patients seek timely access to subspecialty care within a complex delivery system while facing barriers: distance, economics, and clinician shortages. Aim: We examined stakeholder perceptions about solutions to the access challenge. We engaged over 300 referring primary care pediatricians in the evaluation of Access Clinics at an academic children's hospital. Methods: Using an anonymous online survey, we asked pediatricians about their and their patients' experiences and analyzed factors that may influence referrals. Findings: Referring pediatricians reported satisfaction; they provided feedback about their patients' experiences, physician communication, and referral influences. Distance from the Access Clinic does not correlate with differences in referral volume; living in areas with higher child populations and higher median income is associated with more referrals. Referring pediatricians have strong opinions about referrals, are attuned to patient experiences, and desire bi-directional communication. Multiple factors influence referral to and acceptance of Access Clinics, but external influences have less impact than expected.
\end{abstract}

Key words: health care access and delivery; practice transformation; subspecialist shortages

Received 27 July 2015; revised 25 November 2015; accepted 25 April 2016;

first published online 17 May 2016

\section{Introduction}

Pediatric subspecialist shortages in the United States challenge health systems' ability to provide timely access to care (Children's Hospital Association, 2012; Ray et al., 2014). The primary care physician (PCP) coordinates clinical care and resource utilization (Donohoe et al., 1999; Weeks and Wallace, 2003), identifies conditions and

Correspondence to: Dr Matthew D. Di Guglielmo, Clinical Assistant Professor of Pediatrics, Division of Gastroenterology, Hepatology, and Nutrition, Nemours/Alfred I. duPont Hospital for Children, 1600 Rockland Road, Wilmington, DE 19803, USA. Email: mdigugli@nemours.org complaints outside the scope of primary care, and refers to subspecialists or hospitalists (Fernandez et al., 2000; Rappaport et al., 2013). The pediatric subspecialist is a pediatrician who seeks additional fellowship training and specializes in care of more complex patients with a more specific organsystem focus. Due to large regional shortages of fellowship-trained pediatric subspecialists (Children's Hospital Association, 2012), patients experience long wait times for new appointments. In addition, pediatric subspecialists have high volumes of referred patients without complex issues; rather, with common organ-system specific pediatric concerns. Often, PCPs are faced with managing high volumes of low-complexity patients

(C) Cambridge University Press 2016 
but with limited time to address some organsystem specific health needs.

Improving access to care is a focus of significant efforts in today's changing health system (Green et al., 2007; Berwick et al., 2008). Our children's hospital's approach to improving access arose through input of clinicians (subspecialists and generalists), administrators, family advisory council members, and referring PCPs (Sharif et al., 2012). Access Clinics combine an 'Access Pediatrician' (AP), a board-certified general pediatrician embedded within subspecialty divisions who functions as a 'generalist-as-specialist', with specific nurse navigation for patient triage of patients with low-complexity complaints (Di Guglielmo et al., 2013). Side-by-side practice within the subspecialty's clinical space and real-time availability of consultation with subspecialists enhance the AP's expertise. At scheduling, patients or PCPs may request to not see the AP, and these patients are scheduled directly with the subspecialist. However, use of APs can increase access and provide timelier visits while removing barriers to evaluation for patients; as a result, subspecialists are free to see more complex and acutely ill patients.

Evaluating the sustainability of Access Clinics as care delivery transformation requires analysis of the factors driving referrals and assessment of referring physician perceptions (Fernandez et al., 2001; Pletcher et al., 2010). Sustainable transformation relies on understanding practice culture and its effect on practice change, PCP perceptions and needs (Dempster et al., 2015), and the 'buy-in' of referring PCPs (Abatemarco et al., 2008; 2012). The present study aims to determine the referring PCPs' most prevalent perceptions about the AP/Access Clinics as well as to characterize the influence of external factors.

\section{Methods}

\section{Study period, data}

Access Clinic encounters between September 2011 and April 2014 were reviewed; PCP office ZIP code and number of patients referred were recorded. The Institutional Review Board waived approval of the research study, \#306671.

\section{Survey}

Eligible PCPs (referred at least three patients) were individually and anonymously surveyed with online questionnaires (eight questions) using
REDCap software (Harris et al., 2009). Results were collected over 100 days beginning in April 2014. The survey queried perceptions of communication with the Access Clinic, satisfaction with patient care, knowledge about the Access Clinic, and reasons for referral. The survey solicited openended comments ('Please provide any feedback, comments, or questions'). We coded qualitative data by major themes (Crabtree et al., 1998).

\section{Geographic and economic data collection}

Distance between ZIP codes and the Access Clinic were obtained from www.googlemaps.com. Census data on population, households with children $<18$, median income, and number of health practitioners per ZIP code were obtained from www.factfinder2.census.gov. ZIP code data for referring PCP offices were stratified into quartiles by ranking the number of patients referred per PCP. We reported the top quartile.

\section{Statistical analysis}

Descriptive statistics were calculated. In the analysis of ZIP code data, linear regression represented ZIP code rank against each dependent variable, using the best fit trend line $\left(R^{2}\right)$.

\section{Results}

\section{Patient characteristics}

Patients were majority female; aged $<1-17$ years distributed in quintiles of four-year increments above age 1 (Table 1 ). A total of $62.3 \%$ of families were privately insured. Of the 2139 new outpatients, $1438(67.2 \%)$ were referred by their PCP.

\section{Referring PCP characteristics}

PCPs were employed by either the children's hospital's primary care network of practices or were unaffiliated and working in community practices. Three hundred twenty PCPs were eligible (patients referred: range 3-85, median 6.5, IQR 8) including 47 hospital-affiliated PCPs $(14.7 \%)$ and 273 non-affiliated PCPs $(85.3 \%)$. Of note, 21 hospital-affiliated PCPs and 49 nonaffiliated PCPs referred 12 or more patients (top quartile). Surveys were emailed to 41 hospitalaffiliated PCPs (six had left the hospital network at 
Table 1 Demographics; frequency of referrals

\begin{tabular}{lrr}
\hline Category & $N$ & $\%$ \\
\hline Sex & & \\
Female & 1082 & 50.6 \\
Male & 1057 & 49.4 \\
Age (years) & & \\
$\quad<1$ & 423 & 19.8 \\
$1-4$ & 451 & 21.1 \\
$5-8$ & 431 & 20.1 \\
$9-12$ & 414 & 19.4 \\
$13-17$ & 420 & 19.6 \\
Insurance & & \\
Private & 1332 & 62.3 \\
Public & 747 & 34.9 \\
Other & 33 & 1.5 \\
None & 27 & 1.3 \\
Referral source & & \\
Primary Care Physician & 1438 & 67.2 \\
Self-referred & 324 & 15.1 \\
Emergency Department & 127 & 5.9 \\
Other specialists & 173 & 8.1 \\
Other & 8 & 0.4 \\
Multiple sources & 69 & 3.2 \\
\hline
\end{tabular}

the time of the survey) and 103 non-affiliated PCPs. Of the remaining 170 non-affiliated PCPs, 151 were successfully contacted by fax.

\section{Survey response}

Thirty-three hospital-affiliated PCPs and 42 nonaffiliated PCPs responded to the emailed survey; five non-affiliated PCPs responded to the faxed survey invitation. Email response rate was $52.1 \%$ (75/144); overall response rate was $27.1 \%(80 / 295)$. The PCPs in the top quartile responded to the survey at a rate of $51.4 \%(36 / 70)$. PCPs were somewhat [23\%] or definitely [70\%] satisfied, viewed patients having had somewhat [29\%] or very $[63 \%]$ positive experiences, and knew the type of patients appropriate for Access Clinic evaluation (PCPs somewhat [24\%] or definitely [65\%] understood). Reasons for referral were varied, focusing on patient needs and practice limitations, but also family preference, shortened wait times, and prior unsuccessful management. The most common reasons for referral were: 'I felt patient needed appointment sooner than subspecialty could accommodate' (61\%) and 'family requested referral' (58\%). Forty-six percent and $44 \%$, respectively, responded that the reasons for referral were: 'Unsuccessful in managing patient with these symptoms' and 'Beyond scope of practice.' PCPs responses indicated they found follow-up communication from the AP to be helpful (23\% somewhat, $74 \%$ definitely) and $80 \%$ would like to be able to communicate more with the AP, although only $44 \%$ reported contacting the AP after their patient's visit. PCPs indicated direct phone call (35\%), Electronic Medical Record message (21\%), or email (21\%) as top communications preferences.

\section{Qualitative comments}

Of the 80 survey responses, 24 PCPs provided comments $(30.0 \%$, Table 2$)$ : positive experiences about efficient and appropriate care; constructive comments about communication; and critical comments expressing dissatisfaction due to preference for subspecialist care.

\section{Geographic and economic trends}

The study area included 11 urban clusters and three urbanized areas with the remaining regions predominantly rural. PCPs were located in a variety of geographic areas throughout the state (the hospital's primary service area) and region. The top quartile of ZIP codes, ranked by patients per referring PCP (range 3-31, median 5.9, IQR 4.85), contained 21 ZIP codes, with all but one within the state (Table 3). One ZIP code (19902) had unavailable census data.

The five ZIP codes with the most patients referred corresponded to suburban population centers (Table 3, column 3). The ZIP code where the Access Clinic is located, 19803, represented $25.7 \%$ of patients. Examining the next five ZIP codes with the most patients referred, the average distance traveled was 25 miles (range 11-54 miles, median 20 miles, and IQR 10 miles). The five ZIP codes with the most referrals per PCP corresponded to five different urban and suburban population centers (average 21 patients/PCP, range 14-31, median 20.5, IQR 4.6; Table 3, columns 3-5). The average distance traveled from the five ZIP codes was 44.8 miles (range 14-90 miles, median 47 miles, IQR 33 miles; Table 3, column 6).

For the top quartile of PCPs, the PCPs that referred the most patients were no farther away than the PCPs that referred the least patients (Figure 1a, $\left.R^{2}=0.0007\right)$. The lack of correlation extended to the entire cohort of PCPs (data not shown). 
Table 2 Qualitative comments from referring PCP survey

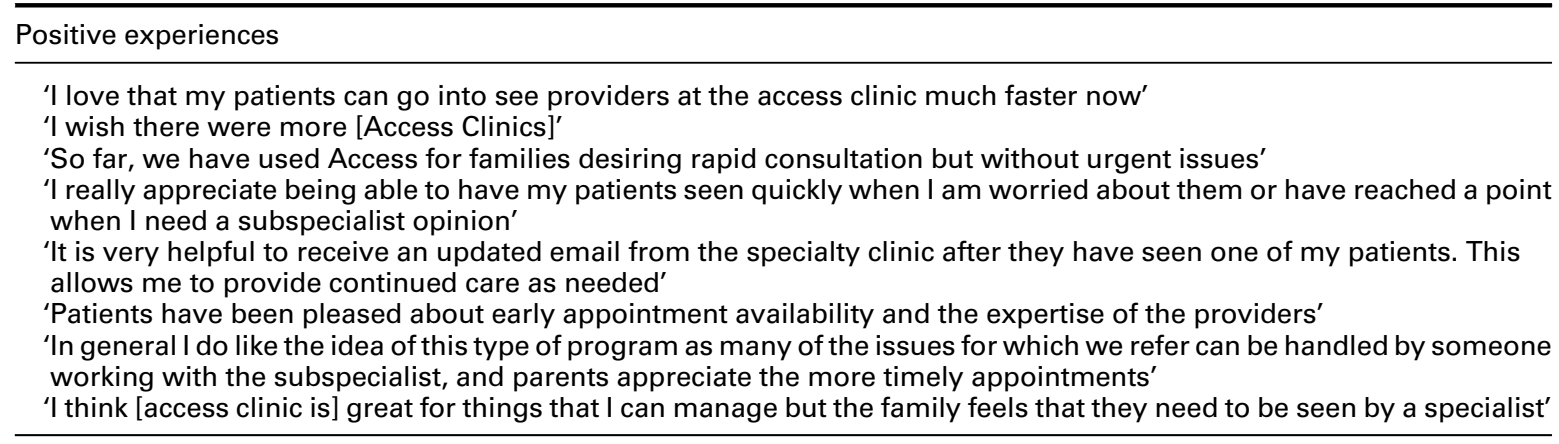

Suggestions for improvement

'Would be nice if there was an option in the [Electronic Medical Record] as to whether I would prefer access clinic or only subspecialty'

'What is best way to refer directly to Access Center of each department?'

'Overall satisfied. Some concerns/questions: would like intermittent updates on what specialty access clinics are available and what the actual wait time is?'

'It would be nice, as the program progresses, to have something printed up for providers making the referral to give us more information on the program and perhaps the scope of typical issues which would be better referred to these programs'

'Access clinic has been very effective in decreasing wait time to be seen. It would be helpful to receive a 'wrap up' letter after labs/studies completed and communicated to the family, particularly if deemed no further follow up appointment is necessary'

Dissatisfaction and criticisms

'I only use the access doctors if I don't believe a specialist is needed but the patients insist. I have been dissatisfied with placement of very complicated patients in the access clinic when we have referred for consult'

'[Access Providers] are helpful when patient has not seen PCP for problem. They are not helpful when PCP has already tried to manage the problem and failed treatment.'

'Support the idea, just that one size does not fit all. I treat most [issues appropriate for AP] in my office. For some of these patients I tell them to request specialist, NOT access, since I feel I have done already what they will do. I also call specialist directly when have specific concerns'

'Maybe access clinics are more appropriate for referrals from non-pediatric practices'

$\mathrm{PCP}=$ primary care physician

ZIP codes with the most frequently referring PCPs had varied median incomes (range \$26 955-\$137617; median \$63 154.50; IQR \$18240), and slightly higher ratios of median income to state median income (\$60119, Figure 1b). The same ZIP codes had higher numbers of health care practitioners (range 105-1266; median 427; IQR 331; Figure 1c) and higher proportions of children to adults (range 13-33\%; median 27\%; IQR 6\%, Figure 1d).

\section{Discussion}

The Access Clinic transforms outpatient subspecialty care delivery at the children's hospital studied. The intent of the Access Clinic is (a) to provide appropriate and comprehensive care when the patient wants it and needs it, and (b) to direct the patient back to the PCP, or on to the subspecialist, as clinically warranted. The referring PCP is essential to the Access Clinic model as co-manager of the patient. Continuous improvement of the innovative care delivery system requires the PCP perspectives identified in the survey to be integrated with other stakeholder input, patient experiences, health outcomes, and cost effectiveness data (Kleinman and Dougherty, 2013).

The primary aim of the study is to examine stakeholder perceptions. Referring PCPs are satisfied with the Access Clinic due to shorter wait 


\begin{tabular}{|c|c|c|c|c|c|c|c|c|c|}
\hline $\begin{array}{l}\text { City/Town in } \\
\text { Delaware unless } \\
\text { indicated }\end{array}$ & ZIP & $\begin{array}{l}\text { Total } \\
\text { patients } \\
\text { referred }(n)\end{array}$ & $\begin{array}{l}\text { Total } \\
\text { PCP } \\
(n)\end{array}$ & $\begin{array}{l}\text { Patients } \\
\text { referred/ } \\
\text { PCP }\end{array}$ & $\begin{array}{l}\text { Distance } \\
\text { (miles) }\end{array}$ & $\begin{array}{l}\text { Homes with } \\
\text { children }<18 \\
(n)\end{array}$ & $\begin{array}{l}\text { Median } \\
\text { income } 2012 \\
(\$)\end{array}$ & $\begin{array}{l}\text { ZIP median income/ } \\
\text { State median income } \\
\text { (\$) }\end{array}$ & $\begin{array}{l}\text { Health care } \\
\text { practitioner } \\
(n)\end{array}$ \\
\hline Georgetown & 19947 & 93 & 3 & 31.0 & 90 & 2078 & 48227 & 0.80 & 172 \\
\hline Clayton & 19938 & 21 & 1 & 21.0 & 47 & 1219 & 70147 & 1.17 & 178 \\
\hline Newark & 19720 & 41 & 2 & 20.5 & 14 & 8033 & 54085 & 0.90 & 771 \\
\hline Newark & 19702 & 295 & 18 & 16.4 & 20 & 7686 & 68547 & 1.14 & 1266 \\
\hline Dover & 19901 & 28 & 2 & 14.0 & 53 & 4539 & 47274 & 0.79 & 495 \\
\hline Hockessin & 19707 & 76 & 6 & 12.7 & 12 & 2186 & 137617 & 2.29 & 564 \\
\hline Avondale, PA & 19311 & 25 & 2 & 12.5 & 16 & 1266 & 92338 & 1.77 & 171 \\
\hline Milton & 19968 & 74 & 6 & 12.3 & 88 & 1102 & 62899 & 1.05 & 399 \\
\hline Wilmington & 19803 & 256 & 21 & 12.2 & 0 & 2504 & 99644 & 1.66 & 725 \\
\hline Wilmington & 19808 & 150 & 13 & 11.5 & 11 & 4591 & 70305 & 1.17 & 654 \\
\hline Seaford & 19973 & 102 & 9 & 11.3 & 95 & 3102 & 47645 & 0.79 & 463 \\
\hline Dover & 19904 & 231 & 21 & 11.0 & 54 & 4254 & 56496 & 0.94 & 547 \\
\hline Townsend & 19734 & 11 & 1 & 11.0 & 33 & 1727 & 83185 & 1.38 & 231 \\
\hline Middletown & 19709 & 129 & 12 & 10.8 & 25 & 5542 & 89852 & 1.49 & 507 \\
\hline Rehoboth Beach & 19971 & 30 & 3 & 10.0 & 95 & 857 & 60479 & 1.01 & 326 \\
\hline Wilmington & 19801 & 20 & 2 & 10.0 & 6 & 2003 & 26955 & 0.45 & 187 \\
\hline Ocean View & 19970 & 10 & 1 & 10.0 & 110 & 446 & 65275 & 1.09 & 105 \\
\hline Newark & 19713 & 217 & 22 & 9.9 & 15 & 3842 & 55685 & 0.93 & 454 \\
\hline Dover AFB & 19902 & 19 & 2 & 9.5 & 59 & Unavailable & Unavailable & Unavailable & Unavailable \\
\hline Wilmington & 19809 & 19 & 2 & 9.5 & 5 & 1691 & 63410 & 1.05 & 264 \\
\hline Smyrna & 19977 & 47 & 5 & 9.4 & 45 & 2876 & 62195 & 1.03 & 237 \\
\hline
\end{tabular}




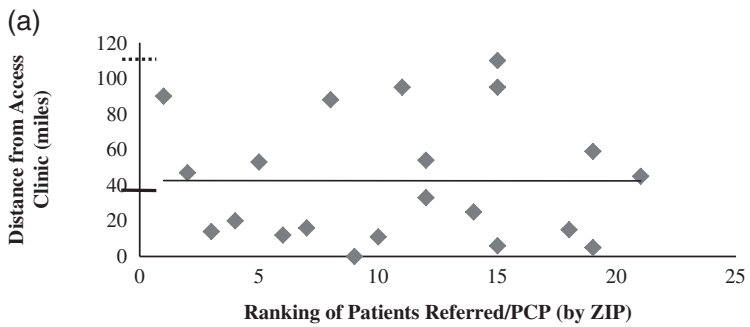

(b)

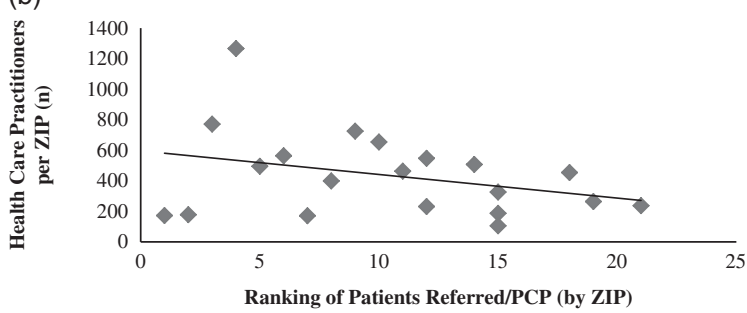

(c)
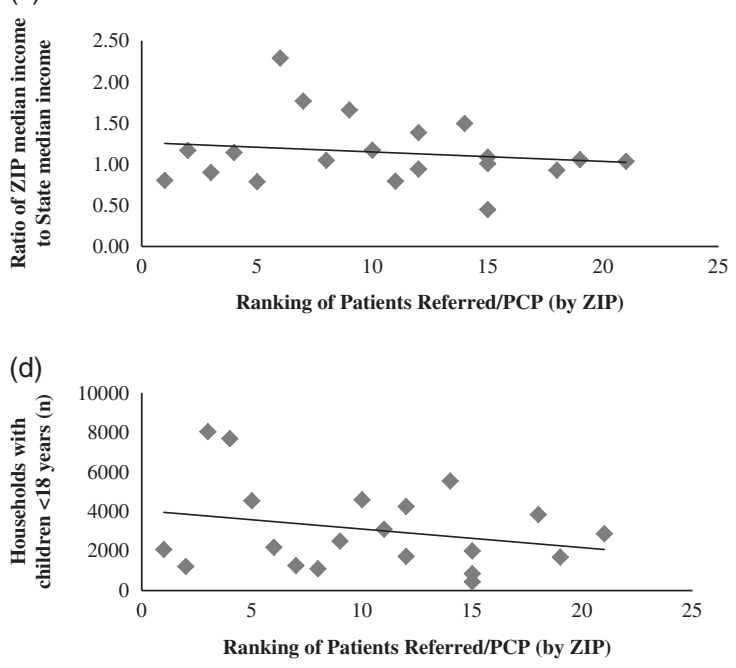

Figure 1 Rank of patients referred per primary care physician (PCP) by ZIP against (a) distance (in miles) of each PCP in Table 3. $Y$-axis solid line: distance cut-off between hospital's primary and secondary service areas; stippled line: between secondary and tertiary. (b) Ratio of ZIP to State median income; (c) number of health care practitioners from each ZIP; (d) number of households with children under 18 for each ZIP. Linear regressions:
(a) $R^{2}=2 \times 10^{-6}$,

(d) $R^{2}=0.0652$.

times and high quality care. The PCP is referring to a 'generalist-as-specialist,' not another PCP (Sharif et al., 2012). PCPs are comfortable with which patients to refer and are satisfied with the Access Clinic. Many PCP comments and survey responses (Table 2) regarding the care their patients experienced provide constructive feedback with themes of family preference, AP expertise, timely care delivery, and bi-directional communication.

Another aim of the study is to understand the influence of external factors on referrals. PCPs refer to the Access Clinic from different population centers and areas with varied PCP densities and diverse demography. Overall, patients came from an average of 25 miles away, but patients referred by the PCPs with the highest referral rate traveled an average of almost 45 miles. Distance was no barrier to these referrals (Figure 1a). Regional factors such as economic characteristics, pediatric population, and distance from the clinic do not appear to affect referral rate. Regression shows regions with higher median income (Figure 1b) and with larger populations of households with children <age 18 (Figure 1c) correlate with greater referrals/PCP. Distance, income, and population did not deter referrals. Other factors, such as quality of care, ease of making appointments, and short wait times may be more likely to influence referral decisions. We conclude that demand for immediate subspecialty care supersedes geographic, population, or economic factors (Figure 1), family demands are paramount to PCP referral patterns, and routine 'in office' subspecialty care by the PCP may be limited by resources or interest.

The demand for subspecialty evaluation in place of, or to complement, PCP evaluation is not unique (Anderson et al., 2007; Martin et al., 2009; Hsu et al., 2012). For the Access Clinic, the involvement of local referring PCPs and subspecialists in the planning stages has been critical to aligning service delivery with demand. In other health care systems, the PCP or generalist nurse may serve as the 'gatekeeper' for subspecialty care (Ramritu et al., 2002; Wilkie, 2013), with more time or resources to see patients with routine complaints, only referring to subspecialists for more complex patient evaluations. International models using general pediatricians with specialty interest, or 'GPSIs' (Salisbury and Rosen, 2007; Martin et al., 2009), if well-designed, show improved access and increased bi-directional communication. In the United States, health care delivery systems that 'train up' community pediatricians to provide 
subspecialty care in the primary care medical home setting have been proposed (Ray Tsai MD, 2014, personal communication).

Limitations of our study include recall bias (surveys), low response rate, and applicability. PCPs with high referrals are more likely to be affiliated thus more familiar with the Access Clinic, introducing potential favorability bias. Non-affiliated PCPs referred more patients but had a poor response rate. Survey participation was not incentivized (Delnevo et al., 2004), affecting response rate. Access Clinics have not been widely implemented or described nationally, so while applicability may be affected by studying one institution, critical information about evaluation of the model will inform academic centers about novel ways of delivering appropriate subspecialty care.

Pediatric subspecialty shortages continue to plague the effective and timely delivery of health care to children (Pletcher et al., 2010; Ray et al., 2014). Successful solutions demand identification of key drivers of referrals, understanding of PCP attitudes (Twamley et al., 2014), and consensus among referring PCPs. Access Clinics can reinforce the 'generalist-as-specialist' paradigm for appropriate patients, improve care quality, and connect subspecialty and primary care practices.

\section{Acknowledgements}

The authors would like to acknowledge J. Fernando del Rosario MD, Christine Chisholm MBA, Joanne Plesnick MBA, J. Carlton Gartner MD, and Iman Sharif MD MPH for their support of the work for this paper.

\section{Funding source}

Work supported by an Institutional Development Award (IDeA) from the National Institute of General Medical Sciences of the National Institutes of Health under grant number U54-GM104941 (PI: Binder-Macleod).

\section{Conflicts of Interest \& Financial Disclosure}

The authors have no relevant financial relationships to disclose. The authors have no conflicts of interest to disclose.

Primary Health Care Research \& Development 2016; 17: 628-635

\section{References}

Abatemarco, D., Kairys, S., Gubernick, R. and Kairys, J. 2008: Expanding the pediatrician's black bag: a psychosocial care improvement model to address the "new morbidities". The Joint Commission Journal on Quality and Patient Safety 34, 106-15.

Abatemarco, D., Kairys, S., Gubernick, R. and Hurley, T. 2012: Using genograms to understand pediatric practices' readiness for change to prevent abuse and neglect. Journal of Child Health Care 16, 153-65.

Anderson, B., Marks, J. Jr., Downs, E., Buckel, T., Adams, D., Enterline, J. and Miller, J. 2007: The Hershey access clinic: a model for improving patient access. Journal of the American Academy of Dermatology 57, 601-3.

Berwick, D., Nolan, T. and Whittington, J. 2008: The triple aim: care, health, and cost. Health Affairs 27, 759-69.

Children's Hospital Association 2012: Pediatric specialists in children's hospitals - 2012; Report, Alexandria, VA.

Crabtree, B., Miller, W., Aita, V., Flocke, S. and Stange, K. 1998: Primary care practice organization and preventive services delivery: a qualitative analysis. Journal of Family Practice 46, 403-9.

Delnevo, C., Abatemarco, D. and Steinberg, M. 2004: Physician response rates to a mail survey by specialty and timing of incentive. American Journal of Preventative Medicine 26, 234-36.

Dempster, N., Wildman, B. and Duby, J. 2015: Perception of primary care pediatricians of effectiveness, acceptability, and availability of mental health services. Journal of Child Health Care 19, 195-205.

Di Guglielmo, M., Plesnick, J., Greenspan, J. and Sharif, I. 2013: A new model to decrease time-to-appointment wait for gastroenterology evaluation. Pediatrics 131, e1632-1638.

Donohoe, M., Kravitz, R., Wheeler, D., Chandra, R., Chen, A. and Humphries, N. 1999: Reasons for outpatient referrals from generalists to specialists. Journal of General Internal Medicine 14, 281-86.

Fernandez, A., Grumbach, K., Goitein, L., Vranizan, K., Osmond, D. and Bindman, A. 2000: Friend or foe? How primary care physicians perceive hospitalists. Archives of Internal Medicine 160, 2902-908.

Fernandez, A., Grumbach, K., Vranizan, K., Osmond, D. and Bindman, A. 2001: Primary care physicians' experience with disease management programs. Journal of General Internal Medicine 16, 163-67.

Green, L., Savin, S. and Murray, M. 2007: Providing timely access to care: what is the right patient panel size? The Joint Commission Journal on Quality and Patient Safety 33, 211-18.

Harris, P., Taylor, R., Thielke, R., Payne, J., Gonzalez, N. and Conde, J. 2009: Research electronic data capture (REDCap) - a metadata-driven methodology and workflow process for providing translational research informatics support. Journal of Biomedical Informatics 42, 377-81. 
Hsu, E., Schwend, R. and Julia, L. 2012: How many referrals to a pediatric orthopaedic hospital specialty clinic are primary care problems? Journal of Pediatric Orthopaedics $32,732-36$.

Kleinman, L. and Dougherty, D. 2013: Assessing quality improvement in health care: theory for practice. Pediatrics 131 (Suppl), S110-119.

Martin, G., Currie, G. and Finn, R. 2009: Reconfiguring or reproducing intra-professional boundaries? Specialist expertise, generalist knowledge and the 'modernization' of the medical workforce. Social Science \& Medicine 68, 1191-198.

Pletcher, B., Rimsza, M., Cull, W., Shipman, S., Shugerman, R. and O'Connor, K. 2010: Primary care pediatricians' satisfaction with subspecialty care, perceived supply, and barriers to care. Journal of Pediatrics 156, 1011-15.

Rappaport, D., Adelizzi-Delany, J., Rogers, K., Jones, C., Petrini, M., Chaplinski, K., Ostasewski, P., Sharif, I. and Pressel, D. 2013: Outcomes and costs associated with hospitalist comanagement of medically complex children undergoing spinal fusion surgery. Hospital Pediatrics 3, 233-41.

Ramritu, P., Courtney, M., Stanley, T. and Finlayson, K. 2002: Experiences of the generalist nurse caring for adolescents with mental health problems. Journal of Child Health Care 6, 229-44.

Ray, K., Bogen, D., Bertolet, M., Forrest, C. and Mehrotra, A. 2014: Supply and utilization of pediatric subspecialists in the United States. Pediatrics 133, 1061-69.

Salisbury, C. and Rosen, R. 2007: Special interest GPs. The Health Service Journal 117, S14-16.

Sharif, I., Gartner, J., Plesnick, J. and Greenspan, J. 2012: Access to subspecialty care: bringing back the specialty of general pediatrics. Journal of Pediatrics 161, 577-78.

Twamley, K., Craig, F., Kelly, P., Hollowell, D., Mendoza, P. and Bluebond-Langner, M. 2014: Underlying barriers to referral to paediatric palliative care services: knowledge and attitudes of health care professionals in a paediatric tertiary care centre in the United Kingdom. Journal of Child Health Care 18, 19-30.

Weeks, W. and Wallace, A. 2003: Time and money: a retrospective evaluation of the inputs, outputs, efficiency, and incomes of physicians. Archives of Internal Medicine $163,944-48$.

Wilkie, P. 2013: Shifting interventions from specialist to general practitioner is not new. But how realistic is it? Quality in Primary Care 21, 63-65. 